\title{
Comparative proteomics analysis of OSNAS1 transgenic Brassica napus under salt stress
}

\author{
KONG Fang ${ }^{1,2}$, MAO ShanJing ${ }^{1}$, DU Kun ${ }^{1}$, WU Mian ${ }^{1}$, ZHOU XiaoYan ${ }^{1}$, \\ CHU ChengCai ${ }^{3} \&$ WANG YouPing ${ }^{1 *}$ \\ ${ }^{1}$ College of Bioscience and Biotechnology, Yangzhou University, Yangzhou 225009, China; \\ ${ }^{2}$ Academy of Biological and Chemical Engineering, Anhui Polytechnic University, Wuhu 241000, China; \\ ${ }^{3}$ Institute of Genetics and Developmental Biology, Chinese Academy of Sciences, Beijing 100101, China
}

Received March 30, 2011; accepted May 16, 2011

\begin{abstract}
Salt stress is one of the major abiotic stresses in agricultural plants worldwide. We used proteomics to analyze the differential expression of proteins in transgenic OSNAS1 and non-transformant Brassica napus treated with $20 \mathrm{mmol} / \mathrm{L} \mathrm{Na}_{2} \mathrm{CO}_{3}$. Total protein from the leaves was extracted and separated through a high-resolution and highly repetitive two-dimensional electrophoresis (2-DE) technology system. Twelve protein spots were reproducibly observed to be upregulated by more than 2-fold between transgenic and non-transformant $B$. napus. These 12 spots were digested in-gel with trypsin and characterized by matrix-assisted laser-desorption/ionization time-of-flight mass spectrometry (MALDI-TOF-MS) to obtain the peptide mass fingerprints. Protein database searching revealed that 5 of these proteins are involved in salt tolerance: dehydrogenase, glutathione $S$-transferase, peroxidase, 20S proteasome beta subunit, and ribulose-1,5-bisphosphate carboxylase/oxygenase. The potential functions of these identified proteins in substance and energy metabolism, stress tolerance, protein degradation, and cell defense are discussed. The salt tolerance of the transgenic rapeseed was significantly improved by the introduction of the OsNAS1 gene from Brazilian upland rice of Oryza sativa (cv. IAPAR 9).
\end{abstract}

Brassica napus, nicotianamine synthase (NAS), salt-stress, differential proteins

Citation: $\quad$ Kong F, Mao S J, Du K, et al. Comparative proteomics analysis of OsNAS1 transgenic Brassica napus under salt stress. Chinese Sci Bull, 2011, 56: 2343-2350, doi: 10.1007/s11434-011-4585-x

As an important oil crop, rapeseed is the largest source of domestic edible vegetable oil. At present, China consumes more edible oils than it can supply; in fact its self-sufficiency rate is only approximately $40 \%$ [1]. Expanding the planting area and improving rapeseed yields are urgent needs. A survey by the United Nations Food and Agriculture Organization suggests that $6 \%$ of the worldwide land area suffers from soil salinization. Approximately $20 \%$ of irrigated agricultural lands are threatened by salinity problems to different degrees, which cause significant decreases in crop yields. With the critical increase in soil salinization, the effective and reasonable use of saline-alkali land has

*Corresponding author (email: wangyp@yzu.edu.cn) become an urgent issue in many countries [2]. Research on the identification of stress resistance genes has focused on expression changes under stress condition, and has identified genes such as penetration regulator synthetic key enzyme genes, ion transport carriers, antioxidant enzyme genes, as well as some transcription factors that regulate gene expression [3]. Under salt stress, plants can maintain stable concentrations that permit cell metabolism by selective absorption, efflux, and regional integration of ions. The expression of nicotianamine synthase gene $(N A S)$ is induced by salt stress and the gene has been proven to have an important role in iron absorption in plants. NAS expression can be used to catalyze and synthesize niacinamide (NA), the synthetic precursor of plant iron carriers, which participates 
in iron ion transport, distribution, and storage. It can also transport other heavy metal ions. Therefore, NA has strong metal resistance effects and capacity for phytoremediation [4]. Many NAS genes have been cloned from plants, including wheat, barley, oats, rice, corn, tomato and Arabidopsis [5-8].

In recent years, proteomics has been applied to analyze the changes in protein expression in rice, wheat, maize, soybean and grape, among others, under salt stress. Moreover, the approach has been used to determine the characteristic expressions of proteins involved in photosynthesis, respiration, protein metabolism and signal transduction when responding to salt stress. The accumulated data can be used for further investigations of the mechanism of salt tolerance in crops [9]. In this study, OsNASI cloned from roots of Oryza sativa cv. IAPAR 9 was transformed into Brassica napus using Agrobacterium tumefaciens-mediated transformation. Subsequently, transgenic plants were selected and the salt stress response of transgenic rapeseed was investigated using proteomics technology.

\section{Materials and methods}

\subsection{Explant preparation}

Brassica napus L. cv. "yangyou 6" was provided by the Jiangsu Institute of Agricultural Science in the Lixiahe District. The seeds were surface-sterilized in $70 \%$ ethanol for $30-60 \mathrm{~s}$ followed by a $15-\mathrm{min}$ rinse with $2 \%$ commercial bleach containing sodium hypochlorite. The seeds were then thoroughly washed 3 times with sterile distilled water. The surface-sterilized seeds were germinated in MS solid medium under fluorescent lights (16 h light/8 h dark, $1300 \mathrm{~lx}$ ) at $24^{\circ} \mathrm{C}$ after dry blotting on sterile filter paper. Young hypocotyls were excised from the 4- to 7-d-old seedlings, cut into $1 \mathrm{~cm}$ segments and grown for $3 \mathrm{~d}$ in pre-culture medium $\left(\mathrm{B}_{0}\right)$ (Table 1$)$ under light $\left(24^{\circ} \mathrm{C}, 1300 \mathrm{~lx}\right)$.

\subsection{Agrobacterium tumefaciens strain and the OsNAS1 plasmid}

The targeting vector harboring OsNASI (Figure 1) was purified

Table 1 Culture medium components for rapeseed transformation

\begin{tabular}{ll}
\hline \multicolumn{1}{c}{ Medium type } & \multicolumn{1}{c}{ Medium components } \\
\hline Pre-culture medium $\left(\mathrm{B}_{0}\right)$ & $\mathrm{MS}+1.0 \mathrm{mg} / \mathrm{L} 2,4-\mathrm{D}+1.0 \mathrm{mg} / \mathrm{L} 6-\mathrm{BA}$, \\
& $\mathrm{pH} 5.8$ \\
Cocultivation medium $\left(\mathrm{B}_{1}\right)$ & $\mathrm{MS}+0.1 \mathrm{mg} / \mathrm{L} 2,4-\mathrm{D}+1.0 \mathrm{mg} / \mathrm{L} 6-\mathrm{BA}+$ \\
& $5.0 \mathrm{mg} / \mathrm{L} \mathrm{AgNO}_{3}, \mathrm{pH} 5.8$ \\
Selection and differentiation & $\mathrm{MS}+0.1 \mathrm{mg} / \mathrm{L} 2,4-\mathrm{D}+1.0 \mathrm{mg} / \mathrm{L} 6-\mathrm{BA}+$ \\
medium $\left(\mathrm{B}_{2}\right)$ & $5.0 \mathrm{mg} / \mathrm{L} \mathrm{AgNO}_{3}+10 \mathrm{mg} / \mathrm{L} \mathrm{Kan}+500$ \\
& $\mathrm{mg} / \mathrm{L} \mathrm{Cef}, \mathrm{pH} 5.8$ \\
Rooting medium $\left(\mathrm{B}_{3}\right)$ & $\mathrm{MS}+0.3 \mathrm{mg} / \mathrm{L} \mathrm{NAA}+10 \mathrm{mg} / \mathrm{L} \mathrm{Kan}+500$ \\
& $\mathrm{mg} / \mathrm{L} \mathrm{Cef}, \mathrm{pH} 5.8$ \\
Seedling medium & $(1 / 2 \mathrm{MS}), \mathrm{pH} 5.8$ \\
\hline
\end{tabular}

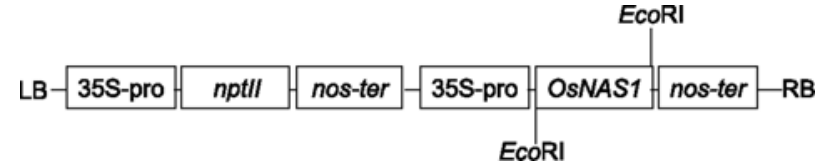

Figure 1 Diagram of the targeting vector harboring OsNAS1. LB, left border; RB, right border; nptII, kanamycin-resistance gene; nos-ter, nos terminator. OsNAS1, nicotianamine synthase gene from upland rice; $35 \mathrm{~S}$ Pro, $35 \mathrm{~S}$ promoter.

from Escherichia coli DH5 $\alpha$ and transformed into Agrobacterium tumefaciens strain LBA4404.

\subsection{Agrobacterium tumefaciens-mediated transfor- mation of $B$. napus}

A single colony of Agrobacterium harboring the OsNAS1 targeting vector was cultured in $2 \mathrm{~mL}$ liquid LB medium for $16 \mathrm{~h}$ at $28^{\circ} \mathrm{C}$ on a shaker. The colony was transferred into $25 \mathrm{~mL}$ of LB medium to expand the culture for 4-5 h. The Agrobacterium culture $\left(A_{600 \mathrm{~nm}}=0.6\right)$ was pelleted by centrifugation and resuspended in liquid Murashige and Skoog (MS) medium. The precultured hypocotyls were removed from the medium $\left(\mathrm{B}_{0}\right)$ and cocultivated in the bacterial suspension for 20-30 min. Following cocultivation, the hypocotyls were removed from the bacterial suspension. The transformed explants were dry blotted on sterile filter paper, placed into the cocultivation medium $\left(\mathrm{B}_{1}\right)$, and maintained for $3 \mathrm{~d}$ at $28^{\circ} \mathrm{C}$ in the dark. For the selection of transformed cells, the explants were moved to the selection and differenttiation medium $\left(\mathrm{B}_{2}\right)$, and transferred into fresh $\mathrm{B}_{2}$ medium every 2-3 weeks. When shoots grew from the callus, the regenerated shoots were excised from the explants and cultivated on rooting medium $\left(\mathrm{B}_{3}\right)$. On the medium containing $1 / 2$ strength MS, the rooted seedling grew stronger. The culture media for the different developmental stages are shown in Table 1.

\subsection{Molecular identification of transformed plants $\left(\mathbf{T}_{0}\right.$ and $\mathrm{T}_{1}$ )}

Total genomic DNA was extracted from leaves of the regenerated plants using the cetyl trimethylammonium bromide (CTAB) method [10]. Polymerase chain reaction (PCR) was performed to confirm the integration of the target gene. The design of the primers was based on the sequence of the target gene, i.e., 5'-CAGGAAGTGATGGAGCATCAG-3'; 5'-TCGTGCACCATCAGCACGTTA-3'. The PCR conditions were: an initial denaturation of DNA at $94^{\circ} \mathrm{C}$ for $5 \mathrm{~min}$; followed by 30 cycles for $30 \mathrm{~s}$ at $94^{\circ} \mathrm{C}$ (denaturing), $30 \mathrm{~s}$ at $55^{\circ} \mathrm{C}$ (annealing), and $1 \mathrm{~min}$ at $72^{\circ} \mathrm{C}$ (extension). Up to $5 \mu \mathrm{L}$ of the amplicons were visualized by electrophoresis on a $1.0 \%$ agarose gel. A putative positive plant was expected to have a band corresponding to an amplicon of $750 \mathrm{bp}$ on the agarose gel. The positive plants were transferred into a greenhouse and fertilized regularly. 
The plants were subjected to vernalization and flowered successively in April and May. Seeds were set after bagging and selfing. Some selfed positive rapeseed plants $\left(T_{0}\right)$ were selected and sown into the soil in mid-October of the same year. After germination and subsequent growth, DNA from leaves of the positive plants was extracted using the CTAB method. PCR was performed to ensure that the selfed seeds were still positive.

Southern blot hybridization was performed using $2.5 \mu \mathrm{g}$ genomic DNA from one negative control and 5 positive rapeseeds digested with the restriction enzyme $B a m \mathrm{H}$ I, visualized through electrophoresis on a $1.0 \%$ agarose gel, and then transferred onto a nylon membrane. The probe derived from the OsNAS1 gene was labeled with digoxigenin, and hybridized according to the procedures of a previous study [11].

\subsection{Growth under salt stress and determination of physiological indexes of $T_{1}$ seeds}

The $\mathrm{T}_{1}$ seeds from the transgenic plants integrated with only one copy of OsNAS1 and the control cv. "yangyou 6" were sterilized. Four groups, each consisting of 10 seeds, were placed on filter paper infiltrated with different $\mathrm{Na}_{2} \mathrm{CO}_{3}$ concentrations $(0,10,20$ and $30 \mathrm{mmol} / \mathrm{L})$. Seed germination was observed, and then the biomass (fresh weight) and the activity of catalase (CAT) and peroxidase (POD) were determined. At the same time, root vigor was tested using the triphenyl tetrazolium chloride method, based on details from a previous study [12]. All the processes were repeated three times.

\subsection{2-DE and mass spectrometry analysis of leaf proteins}

$\mathrm{T}_{1}$ seeds from transgenic and non-transformants were grown under the same conditions for $28 \mathrm{~d}$. The seeds were treated with $20 \mathrm{mmol} / \mathrm{L} \mathrm{Na}_{2} \mathrm{CO}_{3}$ for $9 \mathrm{~d}$. The young leaves from seedlings were washed with sterile water and dry blotted on filter paper prior to the extraction of total protein. The total protein content was determined and analyzed with 2-DE. The method used in our laboratory followed a previously published protocol [13]. The electrophoreses were repeated 3 times. Mass spectrometry and protein identification were performed using the MASCOT software (http://www.matrixscience.com). Results were obtained from protein databases, such as MSDB, NCBinr and Swissport.

\section{Results}

\subsection{Molecular identification of transformants $\left(\mathbf{T}_{\mathbf{0}}\right)$}

For the selection of transformed cells, the rapeseed hypocotyls cocultivated with Agrobacterium for $4 \mathrm{~d}$ were placed on the $\mathrm{B}_{2}$ medium and subcultured every $2-3$ weeks. Cell division in the hypocotyls was profuse. The ends of the hypocotyl cuttings became swollen and calli of different sizes appeared gradually. At certain times, dark green buds were observed. Adventitious buds grew from the calli after 40-50 d. Initially, the buds were green, white, and purple. Gradually, the buds turned white, and ultimately died. However, some buds remained green and further elongated to become seedlings. The seedlings were excised and transferred onto the $\mathrm{B}_{3}$ medium. The rooted seedlings continued to grow on the medium containing $1 / 2$ strength MS, where the roots developed further (Figure 2). This process helped to eliminate shoots that failed to root due to vitrification. Genomic DNA from the putative transgenic plants, untransformed plant leaves (as a negative control), and plasmid DNA containing the OsNAS1 gene (as the positive control) were subjected to PCR to determine the presence of the target gene OsNAS1. The results showed that the OsNAS1 transgenic plants generated bands of $750 \mathrm{bp}$, whereas the non-transgenic control Brassica did not (data not shown). Fifty transgenic plants were obtained and were planted into soil. Seeds set after bagging and selfing. To investigate the integration of the foreign genes in the genome, the genomic DNA of non- transgenic control and transgenic plants, which were identified by PCR, were restriction enzyme digested and hybridized with an OsNAS1 gene probe. The results are shown in Figure 3. Different plants showed different insertion sites and numbers of copies of the OsNAS1 gene in the rapeseed genome.

\section{2 $\mathrm{T}_{1}$ seeds, physiological conditions, and germination of seeds under salt stress}

Seeds from the transgenic plants, identified to have integrated only one copy by Southern blot hybridization, were sown into soil. Total genomic DNA was extracted from the leaves using the CTAB method. The plants shown to be positive by PCR were set seeds $\left(\mathrm{T}_{1}\right)$ after selfing, whereas the negative ones were abandoned. Selected seeds from the different transgenic plant $\left(\mathrm{T}_{1}\right)$ lines and the control cv. "yangyou 6" were placed on filter papers infiltrated with different $\mathrm{Na}_{2} \mathrm{CO}_{3}$ concentrations $(0,10,20$ and $30 \mathrm{mmol} / \mathrm{L})$ after sterilization and were observed for germination. After $5 \mathrm{~d}$, the seeds from the transgenic plants were found to grow better than the control when treated with $10 \mathrm{mmol} / \mathrm{L}$ $\mathrm{Na}_{2} \mathrm{CO}_{3}$ solution. Once the seeds germinated, they grew rapidly and the cotyledons became green. However, the seeds of the control showed slower growth without root formation. The cotyledons stretched out, but did not turn green from the initial yellow color. The growth of the nontransgenic seeds on the filter paper infiltrated with $20 \mathrm{mmol} / \mathrm{L}$ $\mathrm{Na}_{2} \mathrm{CO}_{3}$ was blocked. The transgenic seeds grew normally, although part of the leaves turned yellow. At $30 \mathrm{mmol} / \mathrm{L}$ $\mathrm{Na}_{2} \mathrm{CO}_{3}$, the non-transgenic seeds failed to grow at all, whereas the transgenic seeds did develop beyond germination. In terms of the accumulation of biomass, the fresh weights of the transgenic seeds and the non-transgenic seeds 

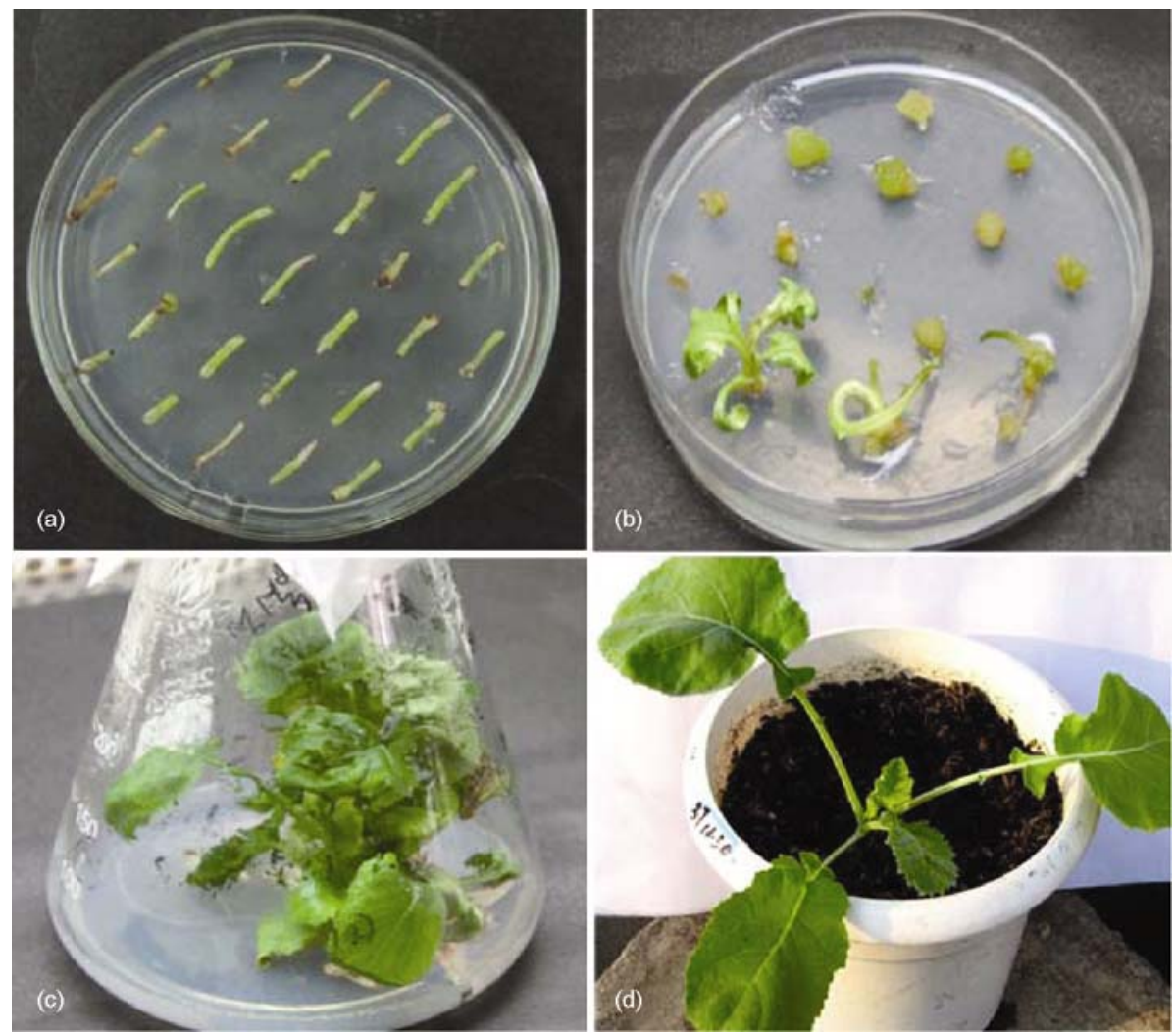

Figure 2 Process of Agrobacterium-mediated transformation of rapeseed hypocotyls. (a) Hypocotyls transformed by Agrobacterium; (b) calli formation and budding; (c) seedling rooting; (d) transplantation of positive plants.

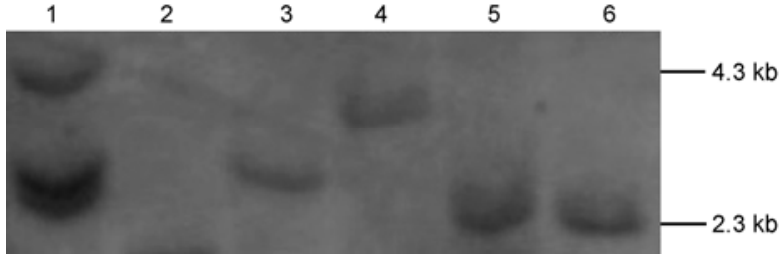

Figure 3 Southern blot hybridization of the OSNAS1 transgenic regenerated plants. Lanes 1, 3-6, DNA from transgenic plants; 2, DNA from on-transgenic plant.

decreased with the increasing $\mathrm{Na}_{2} \mathrm{CO}_{3}$ concentration. However, the fresh weight of the transgenic seeds was heavier compared with that of the non-transgenic seeds (Figure 4(a)). CAT and POD activity in the transgenic plants increased with the increase in $\mathrm{Na}_{2} \mathrm{CO}_{3}$ concentration. The increase was always higher than that in the control cv. "yangyou 6". The enzyme activity in the plants was highest when treated with $20 \mathrm{mmol} / \mathrm{L} \mathrm{Na}_{2} \mathrm{CO}_{3}$ (Figure 4(b) and (c)). Root vigor was reduced as $\mathrm{Na}_{2} \mathrm{CO}_{3}$ concentration increased. However, root vigor in the transgenic plants was higher than in the control (Figure 4(d)).

\subsection{Differential expression of leaf proteins in non- transformant and $O S N A S 1$ transgenic rapeseed}

Based on the above analysis under different $\mathrm{Na}_{2} \mathrm{CO}_{3}$ con- centrations, the seeds of the transgenic and non-transformant plants were sown and grown in pots for $28 \mathrm{~d}$. Salt stress was followed with $20 \mathrm{mmol} / \mathrm{L} \mathrm{Na} \mathrm{CO}_{3}$ treatment for $9 \mathrm{~d}$. Total protein from the leaves were extracted and separated by spot-legible 2-DE technology system with IPG (range 4-7) strips. The processes were repeated three times. On the 2-DE gels, analysis using PDQuest image software revealed similar distribution patterns of total protein in the non-transformant and the OSNAS1 transgenic B. napus. Within the molecular weight ranges 20.1-97.4 kD, the 2-DE detected 254 and 239 protein spots, on average. Twelve high-quality and highly repetitive spots that had greater than 2-fold changes in abundance were identified and treated with tryptic in-gel digestion and characterized by MALDITOF-MS. As shown in Figure 5, 11 proteins (U1-U5 and U7-U12) were clearly upregulated in the OsNAS1 transgenic plants and a new protein (spot N6) was expressed. These 12 spots with significant differences were characterized by peptide mass fingerprinting and matched with proteins in the database through a search of Green Plants in NCBInr using the Mascot application software at the Matrix science website (http://www.expasy.org/tools). A spot was considered positive if $P<0.05$, otherwise it was considered to be negative. Finally, 11 spots with significant differences were obtained (Table 2).

The identified proteins include GST (spot U5), putative 

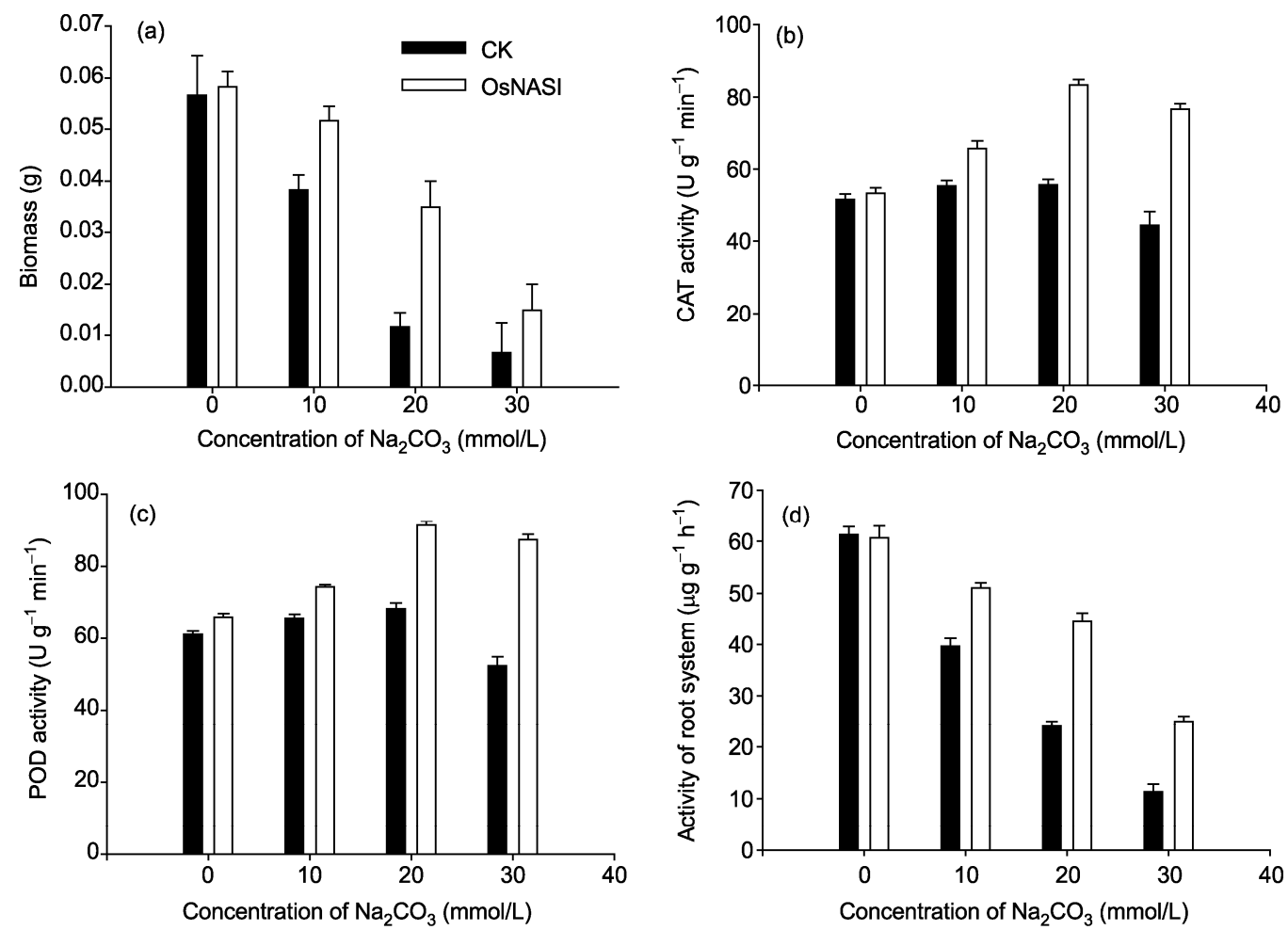

Figure 4 Changes in physiological indexes from OsNAS1 transgenic and non-transgenic (CK) Brassica seeds treated with different $\mathrm{Na}_{2} \mathrm{CO}_{3}$ concentrations. (a) Biomass; (b) catalase (CAT) activity; (c) peroxidase (POD) activity; (d) activity of root system.
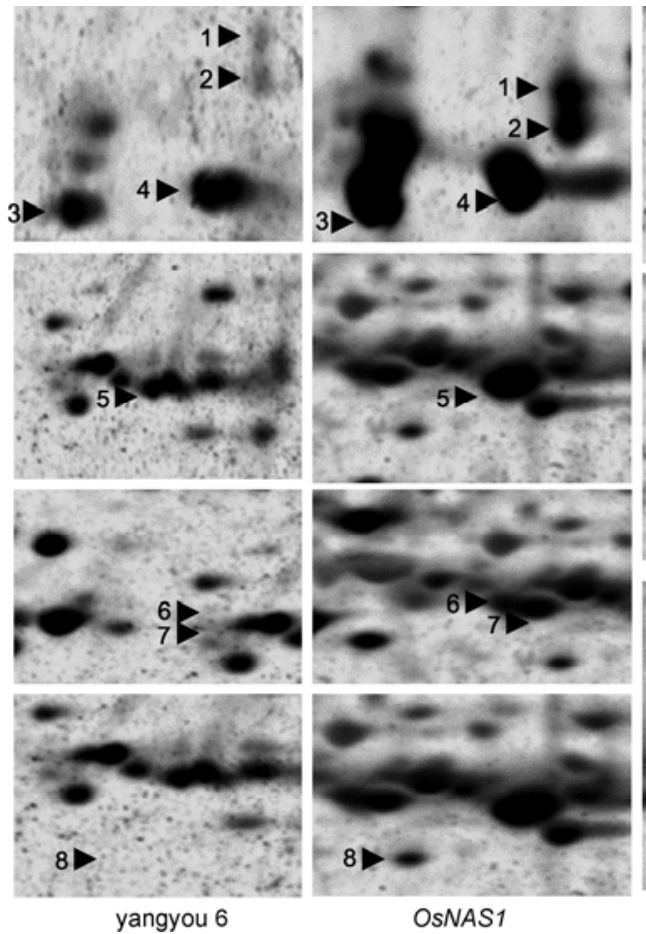

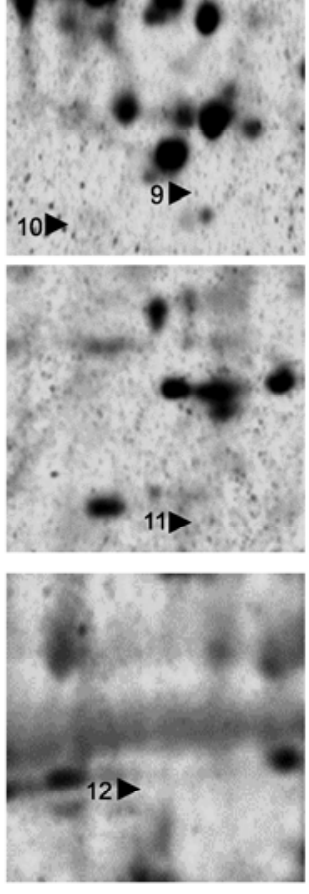

yangyou 6
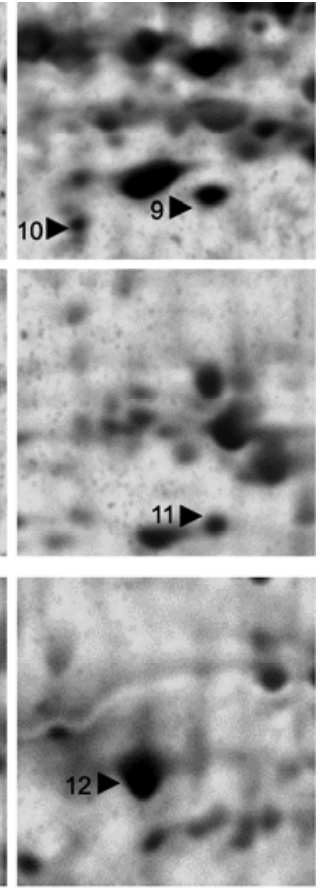

OsNAS1

Figure 5 The enlarged map of protein differences between the OsNAS1 transgenic B. napus $\left(\mathrm{T}_{2}\right)$ and the non-transformant control cv. "yangyou 6" growing under salt stress. 1-12, 2-fold upregulated proteins in abundance in the $O s N A S 1$ transgenic B. napus leaves under salt stress.

dihydrolipoamide dehydrogenase (spot N6), POD (spot U7), ribulose bisphosphate carboxylase/oxygenase (Rubisco; spot U8), 20S proteasome $\beta$-subunit (spot U9), ATP synthase $\beta$-subunit (spot U10), peptidylprolyl isomerase (spot
U12), and 4 proteins of unknown functions (spots U2, U3, $\mathrm{U} 4$, and U11). Among them, dihydrolipoamide dehydrogenase was a newly discovered protein whose expression responded to salt stress. 
Table 2 Hypothetical proteins and putative function of differential proteins in the OsNASI transgenic B. napus

\begin{tabular}{|c|c|c|c|c|c|}
\hline Spots & Species & $\begin{array}{l}\text { Theoretical } \\
\text { MW (kD) }\end{array}$ & pI & $\begin{array}{c}\text { Sequence } \\
\text { coverage }(\%)\end{array}$ & $\begin{array}{c}\text { NCBI } \\
\text { accession ID }\end{array}$ \\
\hline $\mathrm{U} 2$ & Hypothetical protein F8D20.220 (Arabidopsis thaliana) & 31.7 & 9.02 & 22 & gi|77270522 \\
\hline U3 & Retrotransposon protein, putative, Ty3-gypsy subclass (Oryza sativa) & 269.2 & 8.54 & 10 & gi|77556423 \\
\hline $\mathrm{U} 4$ & Hypothetical protein $(O$. sativa) & 28.2 & 11.07 & 25 & gi|77553162 \\
\hline U5 & Glutathione $S$-transferase (Brassica napus) & 24.8 & 5.85 & 40 & gi|87294807 \\
\hline N6 & Putative dihydrolipoamide dehydrogenase ( $O$. sativa, japonica cultivar-group) & 50.9 & 7.01 & 17 & gi|50932201 \\
\hline U7 & Peroxidase (Nicotiana tabacum) & 39.0 & 5.99 & 7 & gi|14031049 \\
\hline $\mathrm{U} 8$ & Ribulose-1,5-bisphosphate carboxylase/oxygenase (B. rapa) & 20.4 & 8.23 & 30 & gi|17852 \\
\hline U9 & $20 \mathrm{~S}$ proteasome beta subunit (A. thaliana) & 63.3 & 5.93 & 29 & gi|21617882 \\
\hline U10 & ATP synthase beta subunit (chloroplast B. napus) & 44.1 & 8.54 & 52 & gi|8745523 \\
\hline U11 & OSJNBa0029L02 (O. sativa) & 20.7 & 9.77 & 51 & gi|39546227 \\
\hline U12 & Peptidylprolyl isomerase (EC 5.2.1.8) ROC4 (A. thaliana) & 28.5 & 8.83 & 33 & gi|20259872 \\
\hline
\end{tabular}

\section{Discussion}

The nicotianamine synthase gene $(N A S)$ has been shown to have a key role in the response to iron deficiency stress in higher plants $[14,15]$. In rice, the involvement of the OsNASI gene in iron metabolism is induced by salt stress. Rice displays three distinct gene expression patterns in response to salt stress and the differential expression of OsNAS1 gene is one of them. In the present study, OsNASI transgenic $B$. napus $\left(\mathrm{T}_{2}\right)$ were found to grow better than the control when treated with $20 \mathrm{mmol} / \mathrm{L} \mathrm{Na}_{2} \mathrm{CO}_{3}$. To identify proteins associated with the salt stress response and to further understand the mechanism of the salt stress response in transgenic plants, a proteomics approach was applied to investigate expression of total leaf proteins in OsNAS1 transgenic rapeseed under salt stress. Through comparative analysis of the protein profiles of transgenic plants and the non-transgenic control, it was found that the expression of proteins related to substance and energy metabolism, stress tolerance, detoxification, peroxide degradation, and protein degradation were upregulated to different extents. This could account for the improved salt tolerance and alkali resistance of the OsNAS1 transgenic plants.

Spot U8, which was identified as Rubisco, was up-regulated in the transgenic $\mathrm{T}_{2}$ plants compared with the control. Studies [16] suggest that Rubisco has diverse roles in specific biological processes in plants, including plant heat resistance, the salt stress response, photorespiration, growth, and glucose metabolism. In rice, Shen et al. [17] observed sheath proteins on 2-DE gels and found that the expression of the small subunit of Rubisco increases within $48 \mathrm{~h}$ after mechanical wounding. After mechanical simulation through pest feeding, Le et al. [18] clearly observed the upregulated expression of the Rubisco small subunit in the leaf of the same rapeseed plant. The result suggests that Rubisco has an important role in the physiology of damage resilience. The results of the present study are in accordance with the aforementioned result, and confirm that Rubisco is upregulated under salt stress.

Spot U9 was identified as 20S proteasome $\beta$-subunit [19]. It is mainly responsible for the ubiquitin-dependent protein degradation pathway in cells. Misfolded proteins are quickly and selectively degraded through the ubiquitin-protease pathway by the $20 \mathrm{~S}$ proteasome, which is dependent on the ATP and helps prevent the aggregation of non-functional and potentially toxic proteins [20]. This process has a special protective role in the response of cells against stress. The upregulated expression of the proteasome subunit suggests that it is very important in the response to salt stress. The protease hydrolysis reaction is likely to be a self-supervised system in terms of preventing stress on cells, and it is indispensable for maintaining cell survival under adverse circumstances.

Spot U5 is glutathione $S$-transferase (GST), which belongs to the class of detoxifying enzymes. Spot U7 was identified as POD, which has a function related to cell defense. The expression of both enzymes was upregulated. Yan et al. [21] found that the expressions of POD, APX, and CAT in leaves and roots were upregulated under salt stress in rice. The overexpression of GST in transgenic tobacco, as observed by Roxas [22], is a preventive measure against oxidative damage under certain conditions, which improves the ability of seedlings to grow under salt stress. In addition, POD overexpression in leaves and leaf buds can provide protection against oxidative stress damage [23]. If POD expression is reverse inhibited, transgenic tobacco undergo early flowering and bud wilting [24]. A proteomics approach was applied to compare and identify the differential proteins of normal flowering and floral reversion buds in longan (Dimocarpus longan Lour.). The result indicated that downregulated POD expression disrupts the balance of free radical production and clearance, which leads to the accumulation of reactive oxygen species (ROS). While flower bud cells suffer from oxidative damage, normal flowering is 
inhibited, and the aging and shedding of floral reversion buds are accelerated [25]. Based on the proteomics analysis and determination of physiologic indexes under salt stress in this study, POD activity was upregulated in the OsNAS1 transgenic rapeseed. This further confirms that increased POD activity ensures that cells maintain low levels of ROS and avoid their toxic effects. Thus, the cells can maintain good salt resistance.

Spot U10 was identified as ATP synthase $\beta$-subunit. ATP synthase is widely distributed in mitochondrial membranes and in chloroplast thylakoid membranes. It participates in oxidative phosphorylation and photophosphorylation reactions. As one of the key enzymes in the energy metabolism in higher plants, it synthesizes ATP; the synthesis is promoted by the transmembrane proton motive force [26]. The $6 \mathrm{kD}$ subunit of the mitochondrial ATP synthase gene was screened out from a rice root cDNA library and proven to be associated with carbonate stress [27]. Certain halophytes reduce cell osmotic potential by transferring inorganic ions into vacuoles to prevent various metabolic processes within the cytoplasm from being disturbed by the high inorganic ion concentrations [28]. Non-halophytes do not have these features. In this study, the expression of the ATP synthase $\beta$-subunit in transgenic $T_{2}$ plants was upregulated by the salt stress treatment. Based on this, we speculated that this spot is involved in ion transport under salt stress, which reduces cell osmotic potential and increases salt tolerance of plants.

Spot N6 was identified as dihydrolipoyl dehydrogenase (DLDH), which was only expressed by the transgenic plants. DLDH belongs to the flavoprotein oxidoreductase family and is an essential component in the multi-enzyme complex called the "pyruvate dehydrogenase system". Under salt stress, the activities of some enzymes in plants associated with basal metabolism are disturbed. To maintain homeostasis under stress, plants need defense mechanisms, such as ion transport, the clearing of oxygen free radicals, and osmotic potential formation. These processes require plants to provide extra energy and DLDH is a foundation enzyme involved in the whole energy metabolism pathway. In this study, the expression of DLDH was upregulated under salt stress. Thus, the transgenic plants needed to consume extra energy to maintain homeostasis when under stress. The increased DLDH expression would enhance energy metabolism, which would offset the extra consumption.

Spot U12 was identified as peptidyl-prolylisomerase (PPIase). Proline is a substituted amino acid. In the polypeptide chain, the peptide bond formed between the peptidyl moiety and proline has two isomers (cis-/trans-); their spatial conformations are different and the rotational isomeric reaction catalyzed by PPIase in vivo is one of the ratelimiting steps in protein folding. PPIase catalysis can accelerate the isomerization of peptidyl-proline. It plays an important role in protein folding and unfolding and it is involved in protein complex assembly/disassembly, protein transport, and regulation of protein activity [29]. In the present study, the PPIase expression of the transgenic plants $\left(T_{2}\right)$ was increased. This enzyme could be a specific protein whose expression is induced by salt stress. It is also involved in the degradation of abnormal proteins and the initiation of protein folding in leaves, which results in normal configuration changes (cis-/trans- or trans-/cis- changes) occurring in the peptide bond. The bond formed between the peptidyl moiety and proline contributes to the formation of a spatial structure with biological function.

Four proteins of unknown function were identified as being upregulated by salt stress by mass spectrometry. Given the limited understanding of the unknown proteins, further investigation is required to identify the relationship between plant chemical defense mechanisms and expression changes of these proteins under stresses. Most importantly, the differentially expressed proteins identified in the present study probably have important roles in the salt stress response. Future research using tandem mass spectrometry and Edman degradation sequencing should identify more proteins and further clarify the role of the protein response to abiotic stress in the transgenic plants.

This work was supported by the Priority Academic Program Development of Jiangsu Higher Education Institutions (PAPD), International $S \& T$ Cooperation of China (1021), the Chinese National Major Program of Transgenic Research (2009ZX08004-002B), and the Scientific Research Foundation for the Introduction of Talent of Anhui Polytechnic University (2010YQQOO7).

1 Wang $\mathrm{H} \mathrm{Z}$. Review and future development of rapeseed industry in China (in Chinese). Chinese J Oil Crop Sci, 2010, 32: 300-302

2 Li Y Z, Shan F X. Tentative study on soil salinization hazards and governance approach (in Chinese). West-China Expl Engin, 2008, 8: 85-88

3 Hao D F, Lan H Y, Chen B D, et al. Introduction of $\mathrm{Na}^{+} / \mathrm{H}^{+}$transporter gene $N H X$ from native halophyte Salicornia spp in Xinjiang into Brassica napus and its salt tolerance (in Chinese). Biotechnol Bull, 2006, 3: 81-84

4 Wiren N V, Klair S, Bansal S, et al. Nicotianamine chelates both FeIII and FeII. Implications for metal transport in plant. Plant Physiol, 1999, 119: 1107-1114

5 Suzuki K, Higuchi K, Nakanishi H, et al. Cloning of nicotianamine synthase in response to Fe nutrition status in Gramineae. Plant Soil, 1996, 178: 171-177

6 Herik A, Koch G, Mock H P, et al. Isolation, characterization and cDNA cloning of nicotianamine synthase from barley, a key enzyme for iron homeostasis in plants. Euro J Biochem, 1999, 265: 231-239

7 Ling H Q, Koch G, Baumlein H. Map based cloning of chleronerva a gene involved in iron uptake of higher plants encoding nicotianamine synthases. Proc Natl Acad Sci USA, 1999, 96: 7098-7103

8 Higuchi K, Tani K, Nakanishi $\mathrm{H}$, et al. The expression of a barley HvNAS1 nicotianamine synthase gene promotor-gus fusion gene in transgenic tobacco is induced by Fe-deficiency in root. Biosci Biotech Biochem, 2001, 65: 1696-1697

9 Shi Y L, Gia Y, Dai S J. Research advances on proteomics of crops under salt stress (in Chinese). Nat Sci J Harbin Normal Univ, 2009, 25: 101-104

10 Murray M G, Thompson W F. Rapid isolation of high molecular weight DNA. Nucleic Acids Res, 1980, 8: 4321-4325

11 Wang Y P, Sonntag K, Rudloff E, et al. Production of fertile transgenic Brassica napus by Agrobacterium-mediated transformation of protoplasts. Plant Breed, 2005, 124: 1-4 
12 Tang Z C. Modern Plant Physiology Experiments Guides (in Chinese). Beijing: Science Press, 1999

13 Kong F, Ge C L, Fang X P, et al. Characterization of seedling proteomes and development of markers to distinguish the Brassica A and C genomes. J Genet Genomics, 2010, 37: 333-340

14 Becker R, Fritz E, Manteuffel R. Subcellular localization and characterization of excessive iron in the nicotianamine-less tomato mutant chloronerva. Plant Physiol, 1995, 108: 269-275

15 Pich A, Manteuffel R, Hillmer S, et al. Fe homeostasis in plant cells: Does nicotianamine play multiple roles in the regulation of cytoplasmic Fe concentration? Planta, 2001, 213: 967-976

16 Dong X L, Zhou J T, Du C H, et al. The progresses of studies in molecular biology of RubisCO (in Chinese). High Technol Lett, 2001, 12: 95-97

17 Shen S, Jing Y, Kuang T. Proteomics approach to identify woundresponse related proteins from rice leaf sheath. Proteomics, 2003, 3: 527-535

18 Le Y T, Li M, Chen Q, et al. Analysis of protein response to mechanical wounding in leaves of Brassica napus cv. Westar (in Chinese). J Plant Ecol, 2008, 32: 220-225

19 Smalle J, Vierstra R D. The ubiquitin 26S proteasome proteolytic pathway. Annu Rev Plant Biol, 2004, 55: 55-60

20 Goldgerg A L. Protein degradation and protection against misfolded or damaged proteins. Nature, 2003, 426: 895-899
21 Yan S P, Tang Z C, Su W A, et al. Proteomic analysis of salt stressresponsive proteins in rice root. Proteomics, 2005, 5: 235-244

22 Roxas V P. Overexpression of glutathione $S$-transferase/glutathione peroxidase enhances the growth of transgenic tobacco seedlings during stress. Nat Biotechnol, 1997, 15: 988-991

23 Gupta A S, Webb R P, Holaday A S, et al. Overexpression of superoxide dismutase protects plants from oxidative stress (induction of ascorbate peroxidase in superoxide dismutase-overexpressing plants). Plant Physiol, 2002, 103: 1067-1073

24 Lagrimini L M, Bradford S, Rothstein S. Peroxidase-induced wilting in transgenic tobacco plants. Plant Cell, 1990, 2: 7-18

25 You X R. Analysis of differential proteomics on longan (Dimocarpus longan Lour.) floral reversion and normal flowering (in Chinese). Doctor Dissertation. Fuzhou: Fujian Agri Forestry University, 2009

26 Paul D. The ATP synthase-A splendid molecular machine. Annu Rev Biochem, 2003, 66: 717-749

27 Zhang X X, Liu S K. Identification and characterization of mitochondrial ATP synthase small subunit gene in Rice (Oryza sativa L.). (in Chinese). Mol Plant Breed, 2003, 1: 605-612

$28 \mathrm{Hu}$ Y, Fricke W, Schmidhalter U. Salinity and the growth of nonhalophytic grass leaves: The role of mineral nutrient distribution. Funct Plant Biol, 2005, 32: 973-985

29 Lu K P, Liou Y C, Zhou X Z. Pinning down the proline-directed phosphorylation signaling. Trends Cell Bio1, 2002, 12: 164-172

Open Access This article is distributed under the terms of the Creative Commons Attribution License which permits any use, distribution, and reproduction in any medium, provided the original author(s) and source are credited. 